\title{
Identification of predation events in wild fish using novel acoustic transmitters
}

\author{
Amy A. Weinz' ${ }^{1}$, Jordan K. Matley', Natalie V. Klinard ${ }^{1,2}$, Aaron T. Fisk' and Scott F. Colborne ${ }^{3 *}$ (0)
}

\begin{abstract}
Background: Acoustic telemetry is a commonly used tool to gain knowledge about aquatic animal ecology through the study of their movements. In telemetry studies researchers must make inferences regarding the movements and the fates of tagged animals. Until recently, predation has been inferred in telemetry data using a variety of methods including abrupt changes in movement patterns or habitat use. An acoustic telemetry transmitter has been developed to detect predation events of tagged animals, and while they have performed well in controlled laboratory trials, literature regarding the application of these novel transmitters in field settings is limited. The objective of this research was to describe the detection data obtained from field studies using predation tags and propose methods to incorporate this information in decision-making about the fate of tagged animals. We implanted 60 yellow perch (Perca flavescens) with predation transmitters and evaluated their spatial use in a receiver array (34 ha) using a combination of centres of activity, roaming indices, and step length measures to examine detection data.

Results: Over 5 months, 19 apparent predation events were identified by the transmitters. Roaming indices and centres of activity revealed a variety of detection patterns, including instances of altered behaviour before and after predation that matched tag-indentified predation events, dropped tags post-predation, and detections that ceased post-predation indicating the predator might have left the array. Based on the observed patterns, probable predation was inferred for 15 of 19 triggered tags, with unclear fates for four fish.

Conclusions: Our study provided a framework to assess the fate of animals tagged with predation transmitters and demonstrate how these tags can contribute to telemetry studies. We showed how detections can be categorized using tag status to compare movement metrics among individuals, provided tools to explore space use surrounding predation events, and synthesized this information to inform uncertainty surrounding tag-identified predation events. Predation tags do not remove all uncertainty about the fate of tagged individuals, but combined with other metrics they increase the likelihood of identifying abnormal movements that could otherwise introduce biased detection histories into studies of small-sized fishes.
\end{abstract}

Keywords: Acoustic telemetry, Survival, Predation, Prey, Tracking, Spatial ecology, Mortality

\section{Background}

Acoustic telemetry is a frequently used method of studying aquatic animal movement to infer behaviour and survival in natural settings [1]. However, as with

*Correspondence: scolborne@sheddaquarium.org

${ }^{3}$ Daniel P. Haerther Center for Conservation and Research, Shedd Aquarium, Chicago, IL, USA

Full list of author information is available at the end of the article all technologies and observation techniques, there are considerations to make when interpreting the data collected. Tracking animal movements and habitat use patterns often requires researchers to evaluate the detection histories of individuals to make judgements about their fates over the course of the study period. These judgements range from deciding if detections represent the movements of a healthy individual (e.g. home ranges and migratory movements), a tag that was expelled or

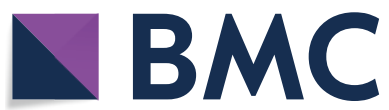

(c) The Author(s) 2020. This article is licensed under a Creative Commons Attribution 4.0 International License, which permits use, sharing, adaptation, distribution and reproduction in any medium or format, as long as you give appropriate credit to the original author(s) and the source, provide a link to the Creative Commons licence, and indicate if changes were made. The images or other third party material in this article are included in the article's Creative Commons licence, unless indicated otherwise in a credit line to the material. If material is not included in the article's Creative Commons licence and your intended use is not permitted by statutory regulation or exceeds the permitted use, you will need to obtain permission directly from the copyright holder. To view a copy of this licence, visit http://creativeco mmons.org/licenses/by/4.0/. The Creative Commons Public Domain Dedication waiver (http://creativecommons.org/publicdomain/ zero/1.0/) applies to the data made available in this article, unless otherwise stated in a credit line to the data. 
detached from an individual, or a deceased individual. It can be particularly difficult to decipher when a tagged animal has been predated, since the tag could still be inside a living predator after consumption (and prior to excretion), introducing potential "predation bias" into the detection data [2]. Yet, predation is a common cause of mortality in the wild and correct distinction between living and predated (or dead) animals is integral to properly interpreting acoustic telemetry data.

A variety of methods have been applied to infer predation in telemetry studies that rely on the identification of atypical detection patterns or sensor data. Sudden changes in temperature have been used to identify the predation of American eels (Anguilla rostrata) by endothermic predators, and further investigation of depthprofile data of the two potential warm-gutted predators in the area led to the identification of the likely predator [3]. However, this approach requires the use of transmitters with additional temperature or depth sensors which are not often available for smaller tags used to track small animals. Other studies have used known movements of likely predators to infer predation. For example, the survival of Atlantic salmon smolts (Salmo salar) has been inferred by comparing movement paths of tagged salmon smolts to those of tagged Striped bass (Morone saxatilis) and using behavioural classification to identify probable predation events [2]. However, this method relies on predators and prey exhibiting discrete movement patterns and having detection data for all potential predators, limiting the broadscale utility of this method to infer predation. As such, inferring predation events based solely on animal movements is challenging but this information can provide critical knowledge about ecological relationships to advise conservation and management programmes.

A recent technological advancement allows for the passive detection of predation using novel acoustic transmitters, hereafter predation tags [4]. The predation tags used in this study (V5D-180 kHz; Vemco Ltd.-InnovaSea Systems Inc., Nova Scotia, Canada) have a small magnet secured by a calcium carbonate resin (i.e. biopolymer) that when dissolved by stomach acids in a predator's gastrointestinal tract following consumption, releases a magnet and results in a change in the tag identification code. Before the tag ID switches, a lag period exists between the time the tagged prey is consumed by a predator and the time the biopolymer is digested. The switch in ID code allows for most pre-predation detections of the tag to be separated from post-predation detections. The tags then remain within the predator's digestive tract until they are excreted. Although the efficacy of these tags has been demonstrated in laboratory settings (4; D. Weber, personal communication), the next steps are to consider how the detection data gathered from these tags can be incorporated into field-based studies (where direct physical observations are not possible) that have begun to employ these tags $[5,6]$.

The goal of this study was to describe the detection data obtained from predation tags using an acoustic array deployed in a temperate freshwater river and suggest means by which researchers can interpret the possible fates of individual fish in wild settings using these new tags. We did this by implanting 60 predation tags into juvenile and small-sized adult yellow perch (Perca flavescens), a ubiquitous prey species, in the Detroit River. We collected the detection histories of these fish over multiple months and used analytical tools to both visualize the locations of activity (centres of activity and movement pathways) and estimate the levels of movement (roaming indices and linear distances between position estimates) occurring before and after tags triggered to indicate a predation event.

\section{Materials and methods}

Study site and acoustic receiver array

This study was conducted from May 2018-January 2019 in a 34 ha segment of the Detroit River $\left(42.23^{\circ} \mathrm{N}\right.$, $-83.10^{\circ} \mathrm{W}$; Fig. 1), a predator-rich connecting channel in the Laurentian Great Lakes (hereafter Great Lakes) where prey species have been shown to exhibit localized movements [7]. The aquatic predator community in this area comprised both resident and migratory species

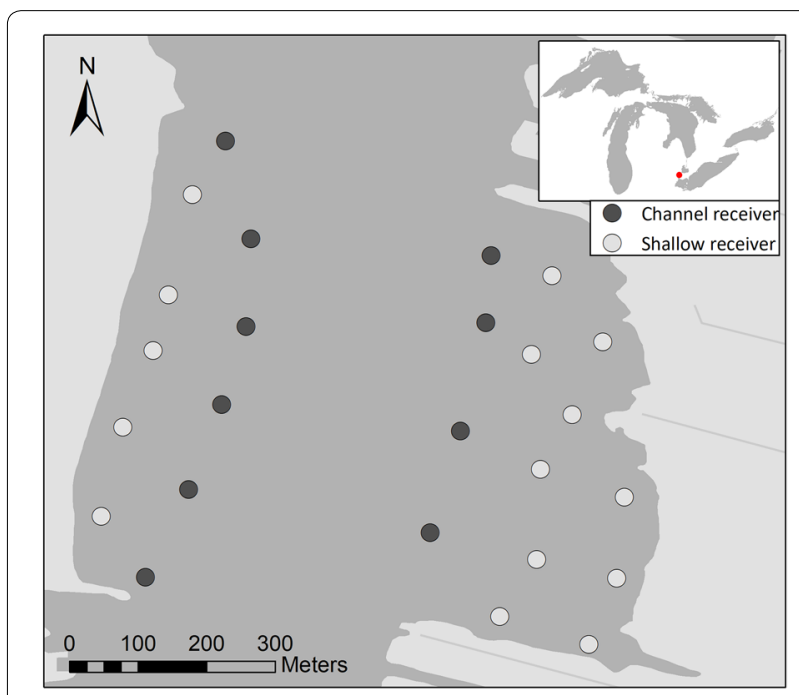

Fig. 1 Map of the acoustic telemetry VR2W-180 kHz receivers deployed in the shallow river margins and along a navigation channel in the Detroit River between the shorelines of LaSalle (eastern boundary) and Fighting Island (western boundary). Red dot in map inset identifies location of study site within the Laurentian Great Lakes 
such as bowfin (Amia calva), largemouth bass (Micropterus salmoides), walleye (Sander vitreus), northern pike (Esox lucius), and muskellunge (Esox masquinongy), among others $[8,9]$. To track tagged prey fish, an array of 21 VR2W-180 kHz acoustic receivers (InnovaSea Systems Inc., Nova Scotia, Canada) was maintained within the focal area. Receivers were spaced 65-270 m apart and varied in depth from $1 \mathrm{~m}$ near shore to $6 \mathrm{~m}$ along the channel. HOBO Pendant temperature loggers (Onset, MA, USA) monitored water temperature in the study site and reported a temperature range from 0 to $27^{\circ} \mathrm{C}$ during the period (May 2018-January 2019) covered in this study. The Detroit River is a connecting channel of the Great Lakes and experiences more consistent depth and flow than a typical large river. Mean water velocity ranged from 0.20 to $1.14 \mathrm{~m} / \mathrm{s}$ throughout the study period based on measurements provided every $12 \mathrm{~min}$ (US Geological Survey monitored at Fort Wayne, MI; https://nwis.water data.usgs.gov/nwis/uv?).

\section{Fish capture and predation tag implantation}

Sixty yellow perch (103-190 mm total length, 13-81 g wet weight) were implanted with V5D-180 kHz predation tags ( $0.68 \mathrm{~g}$ in air; nominal delay of $300 \mathrm{~s} ; 173$ day tag life; InnovaSea Systems Inc., Nova Scotia, Canada) in May $(n=40)$ and July $(n=20) 2018$. We aimed to tag small fish that would be vulnerable to predation from multiple predators. Maximum tag burden (tag weight relative to fish weight) was $5.23 \%$, which is within acceptable ranges based on recent studies of other small fish species $[7,10$, 11]. Prior to implantation, tags were tested to verify that the proper pre-predation ID code was being transmitted. Fish were captured within the study site using a boat electrofisher, held for a maximum of $15 \mathrm{~min}$ in a cooler with ambient river water, and transferred to a larger research vessel for surgical tag implantation. The first six fish tagged were anaesthetized in a buffered solution of tricaine methanesulfonate (MS-222; $100 \mathrm{mg} / \mathrm{L}$ ) and the rest were electrosedated using a PES unit to decrease fish handling and recovery times overall $([12,13] ; 4 \mathrm{~s}$ pulsed DC, $100 \mathrm{~V}, 30 \mathrm{~Hz}$, and 25\% duty cycle; Smith-Root Inc, Washington). We examined data for fish tagged using both methods and did not find any discernable patterns in predation or habitat use, as such these methods were not considered as factors in analyses. To our knowledge there is no published literature indicating chemical or electrical anaesthetics are related to differential predation following release. Once anaesthetized, the fish's total length and weight were measured and they were transferred to a v-shaped cradle where a continuous stream of water flowed over their gills throughout the surgery. A mid-ventral incision of approximately $10 \mathrm{~mm}$ was made to the left of the abdominal midline and anterior to the pelvic fins. A tag was inserted through the incision into the body cavity and gently pushed anteriorly. The incision was closed with two independent sutures using size 5-0 needles (Ethicon coated VICRYL Plus Antibacterial) and a 3-2-2 knot. The fish recovered for a minimum of $15 \mathrm{~min}$ in an aerated holding tank with fresh river water until normal activity was resumed after which they were released as close to the initial point of capture as possible. Surgical equipment, surfaces, and tags were cleaned with a $10 \%$ solution of betadine prior to each individual surgery. All surgeries in this study were carried out by a single person, therefore, no surgeon effects were considered.

\section{Predation stage classification}

For this study, we focused on tags that indicated a predation event, in part because the focus of this paper was to describe the detection data gathered from predation tags to infer the fate of individuals more so than to consider ecological questions about predated and non-predated yellow perch. To delineate the detection histories of the triggered predation tags so that they could be compared amongst each other, we devised four stages to classify the detections from the tags: (1) non-predated, which represented the behaviour of the tagged perch prior to predation; (2) lag period, which included the $24 \mathrm{~h}$ period prior to the first post-predation detection and potentially combined prey and predator behaviour during the time it takes for the tag ID to switch (i.e. signal lag); (3) predated $<24 h$, which indicated the 24 -h period after the first post-predation detection during which time the predators movements were detected; and (4) predated $>24 \mathrm{~h}$, which accounted for the remainder of the detection data, during which time the likelihood of the tag being expelled by the predator increases depending on variable retention times that can be dependent on factors such as water temperature, predator size, predator species, and meal size [2, 4]. A period of $24 \mathrm{~h}$ was chosen for the lag period to span the maximum time for digestion of the prey and biopolymer to occur $(<24 \mathrm{~h})$, which varies based on temperature and prey size [4]. This was a conservative time period, as manufacturer testing of the production version of the predation tag (that differs from those tested in by Halfyard et al.; 4) had a mean ( \pm S.D.) signal lag of $5.8( \pm 2.6) \mathrm{h}$ at $13{ }^{\circ} \mathrm{C}(\mathrm{D}$. Webber, personal communication). Furthermore, these same manufacturer tests $(n=20$ tags) reported a single false positive, i.e. the predation tag switched to the predation ID without predation occurring, on day 111 of a 299-day trial with fish held at $20^{\circ} \mathrm{C}$.

\section{Data analysis}

We examined behavioural variation across triggered tags using three space use metrics: roaming index values, 
movement pathways, and step lengths of movement distances. These measures were chosen because they best suited the array configuration in our particular study system and do not represent the only analyses that could be applied to this type of detection data. Indeed, we encourage researchers to consider measures that are suitable for their study systems but believe the principles demonstrated here are broadly applicable across receiver and array configurations.

Space use was estimated using a roaming index, calculated as the number of unique receivers a fish was detected on within $2 \mathrm{~h}$ intervals divided by the total number of receivers in the array $(n=21 ;[14])$. A roaming index value of 0 indicated the tag was not detected on any available receivers, while a value of 1 meant it was detected on all available receivers.

To visually assess changes in behaviour, movement paths were plotted using centres of activity (COA; [15]) which are short-term position estimates calculated as averaged coordinates of each receiver that detected an individual tag within 30-min time intervals. A 30-min timestep was chosen after visual analysis of COAs calculated with different timesteps $(5,15,30$, and $120 \mathrm{~min})$. Because COAs represent an average of positions throughout the chosen timestep a minimum of two detections per timestep were required; this also significantly reduced the possibility of false detections occurring when the signals from multiple tagged animals in the same area collide and create an incorrect identification code [16]. Following the calculation of each COA, positions were plotted and lines were used to connect successive COA positions to provide an estimate of linear movement pathways.

The COA position estimates were used to estimate the distances moved before and after apparent predation by summing the step lengths between COAs. Centres of activity in the predated $<24 \mathrm{~h}$ and predated $>24 \mathrm{~h}$ stages were combined into one "predated" group. For each day, distances between successive position estimates were calculated and provided the total distance moved in metres for each calendar day. A minimum of two COAs were required on each day for step lengths to be calculated. Stationary tags with a distance moved of $0 \mathrm{~m}$ were removed from the analysis. The final day of detections for each status was omitted from these calculations; for the non-predated group this occurred because presumably the predation event happened at some point during that final day and for the predated group this was the day the tag was possibly excreted by the predator. If there was only a single day with predation status transmissions $(n=5)$, stepwise calculations were included for this single day.
Patterns in the spatial metrics of triggered tags were examined to inform uncertainty surrounding identified predation events and assign a fate to each outcome (framework outlined in Table 1). A fate of predated was assigned with the most confidence when a distinct change in movement patterns occurred during the signal lag and predated $<24 \mathrm{~h}$ stages of detections followed by an eventual decrease in activity indicative of a dropped (i.e. excreted or expelled tag) tag from the predator's gut. A fate of predated was also assigned when there were consistent movement patterns across the phases of the predation event and the tag eventually appeared to be stationary, i.e. excreted from a predators digestive tract. Essentially, in any scenario where a predation event occurred and eventually the tag appeared to be stationary, a fate of predated was assigned. Conversely, when movement patterns were consistent before and after the tag triggered and the tag never appeared to be dropped, a fate of unclear was assigned. In this case, it is difficult to decipher between a tag falsely triggering (i.e. false positive, see below) inside a healthy individual or a true predation event where the tag was eventually dropped outside the detection range of receivers. However, manufacturer tests of the same version of predation tags used here $(n=20)$ reported a false positive rate of $5 \%$, with a single false-positive switch occurring after 111 days (D. Weber, personal communication). When few detections occurred post-predation, a fate of predated was assigned because the tag was most likely consumed by a more mobile predator that left the study area soon after the tag triggered or excreted the tag without detection. Predation scenarios where few post-predation detections occurred were unlikely to be false positives because we expected that a falsely triggered tag would most likely continue to be detected in the receiver array unless the tag completely malfunctioned (triggered predation and then ceased to function at all), which was not mentioned to have occurred in any laboratory testing performed. However, in scenarios where there are too few detections overall, a fate of unclear was assigned based on a conservative approach that favoured underestimating predation with higher confidence in fate to one that would infer higher predation levels with less certainty. False positives were likely to have occurred in scenarios where the tag appeared stationary before the tag triggered (i.e. the tag was triggered in a tagged individual that had expelled the tag or died). It is also possible that the tags failed to identify predation (i.e. false negative), however, this is unlikely due to manufacturer testing and quality control (e.g. 4). Due to different possible predators and detection patterns, false negatives would be difficult to identify unless the detection pattern had distinct changes in behaviour 
Table 1 Summary of classification scheme to infer fates based on predation transmitters

\begin{tabular}{|c|c|c|c|}
\hline Fate & Transmitter state & Movement patterns & Notes \\
\hline Predated & Code switched & $\begin{array}{l}\text { Distinct changes in spatial use (sometimes followed } \\
\text { by a drop in spatial use) }\end{array}$ & $\begin{array}{l}\text { Sudden changes in movement patterns during } \\
\text { early phases of predation event and continued } \\
\text { detections could be inferred as a resident predator } \\
\text { that remains in the area. Sometimes followed by } \\
\text { reduced activity where tag appears stationary, likely } \\
\text { indicative of the tag being expelled from the preda- } \\
\text { tor's digestive tract. }\end{array}$ \\
\hline Predated & Code switched & $\begin{array}{l}\text { Similar spatial use throughout first three phases of } \\
\text { predation followed by decreased activity }\end{array}$ & $\begin{array}{l}\text { Despite no changes in spatial use, the occurrence } \\
\text { of a code switch as well as eventual reduced } \\
\text { overall activity is indicative of a tag that has passed } \\
\text { through a predator's digestive system and been } \\
\text { expelled. }\end{array}$ \\
\hline Predated & Code switched & Few detections post-predation & $\begin{array}{l}\text { Little movement pattern information for predators to } \\
\text { infer fate based on behavioural changes, likely the } \\
\text { outcome when there are migratory predators that } \\
\text { move away from focal areas shortly after preda- } \\
\text { tion or in studies with fewer receivers. Unlikely to } \\
\text { be false positive which would result in continuous } \\
\text { detections in array unless tag completely malfunc- } \\
\text { tioned }\end{array}$ \\
\hline $\begin{array}{l}\text { Unclear (pre- } \\
\text { dated or false } \\
\text { positive) }\end{array}$ & Code switched & $\begin{array}{l}\text { Similar spatial use throughout phases of predation or } \\
\text { few detections pre- and post-predation }\end{array}$ & $\begin{array}{l}\text { Increasing possibility of a false positive as movement } \\
\text { patterns remain consistent after a predation event } \\
\text { was identified. If too little detection data exists } \\
\text { overall, it is hard to draw any conclusions with } \\
\text { certainty. Based on laboratory trials, false positives } \\
\text { are possible, but relatively rare }\end{array}$ \\
\hline Non-predated & Non-predated code & No drastic changes & $\begin{array}{l}\text { Assumes that fish are regularly detected during } \\
\text { transmitter lifespan. Fish that exhibit a change in } \\
\text { behaviour immediately prior to exiting the study } \\
\text { area were likely predated but undetected due to } \\
\text { signal lag period or immediate emigration }\end{array}$ \\
\hline False positive & Code switched & Tag appears to be stationary prior to code switch & $\begin{array}{l}\text { Based on laboratory trials it is unlikely, but possible, } \\
\text { that tags will falsely identify predation after a } \\
\text { tagged fish dies. Tag will likely appear stationary } \\
\text { before the code switches }\end{array}$ \\
\hline False negative & Non-predated code & Distinct changes in spatial use & $\begin{array}{l}\text { Unlikely based on laboratory trials [4]. Difficult to } \\
\text { decipher from a change in the tagged individual's } \\
\text { movement patterns (e.g. ontogenetic or seasonal } \\
\text { shifts in diet and habitat use) }\end{array}$ \\
\hline
\end{tabular}

followed by detection patterns that represent a dropped tag.

\section{Results}

All 60 tagged yellow perch were detected after release, producing 501,277 detections from 5 May 2018-15 January 2019 , the date at which all tags had reached their maximum lifespan. The mean number of detections for all 60 tags was $8354 \pm 9084$ (mean \pm S.D.), ranging from 119 to 51,474 detections, and tags were detected for a mean of $96.9 \pm 72$ days, ranging from 0.8 to 224.8 days. A total of 19 apparent predation events (i.e. the ID code of the tag switched) were detected (31.7\% of tagged fish; Table 2; Fig. 2) between May and September. Mean water temperature at time of the first post-predation detection (which does not always represent the temperature during the signal lag period if gaps in detections occurred) was
$22.6 \pm 3.2^{\circ} \mathrm{C}$ (range $15{ }^{\circ} \mathrm{C}-26{ }^{\circ} \mathrm{C}$ ). Tagged perch that were apparently predated were detected for 0.7-98.9 days prior to the code switch ( $36 \pm 35.4$ days; mean \pm S.D.; Table 2 ). Out of 69,445 post-predation detections, there were four instances in which tags (YP12 and YP26) reverted back to their pre-predation transmission codes for 1-2 detections, either representing momentary tag reversions, as seen in laboratory studies (A. Fisk, unpublished observations), or the product of transmission collisions from multiple tags or environmental noise interference.

Using COAs to estimate the daily distances moved within the array, we found that distance estimates for triggered tags in the non-predated group were available for an average of 19 days (range 1-53 days; Table 3). In comparison, distance estimates for tags in the predated group were available for an average of 3 days (range 
Table 2 Summary of acoustic detections for apparently predated tagged yellow perch in the Detroit River

\begin{tabular}{|c|c|c|c|c|c|c|c|}
\hline Tagging group & Fish ID & Total length $(\mathrm{mm})$ & Total detections & Total receivers & $\begin{array}{l}\text { Days } \\
\text { with detections }\end{array}$ & $\begin{array}{l}\text { Timespan } \\
\text { detected } \\
\text { (days) }\end{array}$ & $\begin{array}{l}\text { Total timespan } \\
\text { detected (days) }\end{array}$ \\
\hline \multirow[t]{12}{*}{ May 2018} & YPO2 & 126 & $17,389 / 136$ & $16 / 4$ & $74 / 14$ & $98.9 / 80.6$ & 179.9 \\
\hline & YP10 & 108 & $2703 / 151$ & $17 / 13$ & $11 / 3$ & $10 / 6.4$ & 16.5 \\
\hline & YP12 & 182 & $3276 / 1295$ & $13 / 6$ & $55 / 50$ & $53.9 / 58.4$ & 113.1 \\
\hline & YP17 & 115 & $2963 / 3$ & $15 / 2$ & $33 / 3$ & $62.1 / 82.1$ & 153.5 \\
\hline & YP19 & 115 & $11,778 / 1696$ & $14 / 2$ & $85 / 22$ & $87.3 / 92.1$ & 180.0 \\
\hline & YP22 & 118 & $2870 / 275$ & $12 / 9$ & $19 / 4$ & $18.3 / 3.2$ & 21.5 \\
\hline & YP23 & 176 & $703 / 50,771$ & $15 / 8$ & $2 / 180$ & $1 / 179$ & 180.0 \\
\hline & YP26 & 175 & $5671 / 107$ & $7 / 1$ & $31 / 9$ & $30.5 / 21.4$ & 53.0 \\
\hline & YP33 & 181 & $116 / 28$ & $6 / 6$ & $2 / 2$ & $0.7 / 0.9$ & 25.0 \\
\hline & YP34 & 118 & $575 / 443$ & $6 / 8$ & $3 / 4$ & $2.4 / 2.4$ & 4.8 \\
\hline & YP38 & 133 & $12,750 / 22$ & $10 / 6$ & $90 / 2$ & $95.4 / 1.1$ & 96.6 \\
\hline & YP39 & 140 & $13,025 / 561$ & $11 / 1$ & $84 / 13$ & $93.5 / 85.9$ & 179.9 \\
\hline \multirow[t]{11}{*}{ July 2018} & YP42 & 106 & $377 / 36$ & $2 / 4$ & $4 / 2$ & $2.8 / 0.5$ & 3.8 \\
\hline & YP43 & 160 & $1548 / 2364$ & $8 / 3$ & $35 / 58$ & $37.2 / 131.4$ & 168.6 \\
\hline & YP44 & 180 & $2283 / 1206$ & $10 / 9$ & $27 / 53$ & 26.1/153.8 & 179.9 \\
\hline & YP47 & 160 & $4038 / 11$ & $11 / 1$ & $29 / 1$ & $28.3 / 0.2$ & 29.4 \\
\hline & YP51 & 103 & $597 / 8266$ & $4 / 2$ & $4 / 44$ & $2.6 / 132$ & 134.6 \\
\hline & YP52 & 109 & $239 / 2037$ & $2 / 1$ & $3 / 47$ & $1.7 / 146.9$ & 148.6 \\
\hline & YP54 & 154 & $640 / 33$ & $7 / 2$ & $32 / 5$ & $31.4 / 138.1$ & 169.7 \\
\hline & Mean & 139.9 & 4396.9/3654.8 & $9.8 / 4.6$ & $32.8 / 27.2$ & $36 / 69.3$ & 107.3 \\
\hline & S.D. & 29.4 & $5264.8 / 11,567.7$ & $4.6 / 3.5$ & $30.6 / 42.3$ & $35.4 / 63.6$ & 71.2 \\
\hline & Range (pre) & $103-182$ & $116-17,389$ & $2-17$ & $2-90$ & $0.7-98.9$ & $3.8-180$ \\
\hline & Range (post) & & $3-50,771$ & $1-13$ & $1-180$ & $0.2-179$ & \\
\hline
\end{tabular}

Data for pre-predation and post-predation are separated by/for applicable metrics. Days with detections indicates the number of unique days the ID code was detected in the array. Timespan detected indicates the timespan the ID code could have been detected in the array based on the difference between the release date and time and the timestamp of the last detection of the pre-predated ID and the difference between the first and last detection timestamp of the post-predated ID. Total timespan detected is the difference between the date and time of the last detection of the post-predation ID and the release date and time

1-18 days). Across all 19 perch, the mean ( \pm S.D.) daily distances moved in the non-predated group was $516.0 \pm 421.8 \mathrm{~m}$, compared to $556.6 \pm 677.5 \mathrm{~m}$ in the predated group. However, the change in daily movements between the non-predated and predated groups was not uniform across all tags.

Combining the predation tag signals and the spatial use metrics from above, 15 fish (of 19 with predation signals) were assigned a fate of predated. A further four individuals were assigned fates of predated based on tags alone (i.e. unclear; Table 4) because they had too few detections to make inferences based on other metrics.

Distinct changes in space use and movement patterns were not observed across all predated yellow perch. Rather, a number of scenarios were associated with fish that were indicated as predated by the tags. To demonstrate the range of detection profiles, we briefly outline six of the triggered tags and our rationale for interpreting the fate of each individual (Fig. 3; see Figs. 4 and 5 for roaming indices and COAs of the remaining 13 triggered tags):
- Tag YP10 was assigned a fate of predated. It exhibited a distinct increase in roaming index values, visual changes in space use within the array, and an increase in daily step lengths (Fig. 3a, b). This included movements across the navigation channel that were not typical tagged perch in this study. It appeared to briefly re-enter the study area after a gap in detections and then left permanently. Identification of predation of this fish would have likely been possible using the analytical metrics without the use of predation tags.

- Tag YP22 was assigned a fate of predated. Instead of increased spatial use (i.e. roaming index), the location of activity moved to the south end of the array after the code switch (Fig. 3c, d). It is possible that this fish would have been classified as predated using analytical methods, but if not then it could have been inferred that this yellow perch had shifted its distribution, incorrectly describing aspects of perch ecology (e.g. seasonal movement to follow food sources). 


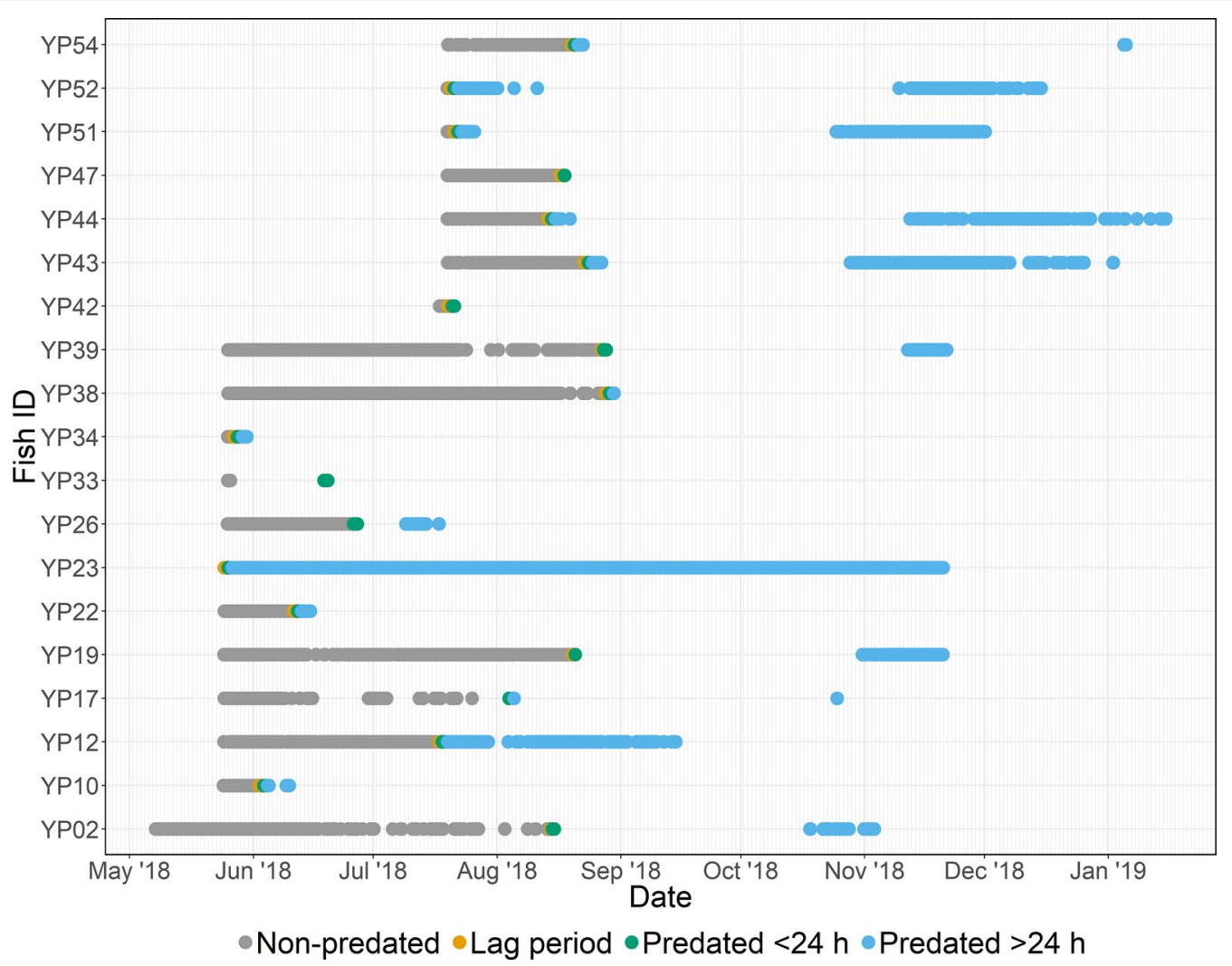

Fig. 2 Detections of apparently predated yellow perch in the Detroit River. Colours differentiate the stages of the predation event: grey indicates perch detections, orange indicates detections within $24 \mathrm{~h}$ before the first post-predation detection, green indicates detections within $24 \mathrm{~h}$ after the first post-predation detection, and blue indicates the remainder of the detections (including those of expelled tags)

- Tag YP23 was assigned a fate of predated. In comparison to the tags that showed changes in space use, Tag YP23 was predated almost immediately after release as indicated by the absence of non-predated detections. It was subsequently detected on a single receiver for 178 days, consistent with a transmitter passing through the digestive system of a predator and being expelled within range of a receiver station (Fig. 3e, f). Without the predation tag, this tag likely would have been inferred as a surgical artefact, i.e. tag lost through incision or acute post-surgical death, and removed from analysis.

- Tag YP39 was assigned a fate of predated. Tag YP39 did not exhibit a clear change but was detected on a single receiver for a period of 87 days after apparent predation, which is a detection pattern consistent with a predator-expelled tag (Fig. 3g, h). Without a predation tag the fate of this fish could have included predation, tag loss, or other cause of death.

- Tag YP38 was assigned a fate of predated. Tag YP38 was triggered 95 days after tagging. Space use did not change post-predation (Fig. 3i, j), but detections ceased 2 days after the tag was triggered, indicating that the predator likely moved out of the receiver array. Without a predation tag, the other metrics applied (roaming index, movement pathways, and step length distances) were unlikely to indicate a probable predation event. Instead, it is likely that we would have assumed this fish migrated out of the study site on its own, possibly as part of seasonal shifts in habitat use.

- Tag YP42 was assigned a fate of unclear. Tag YP42 triggered 2 days post-release but detections ceased on the fourth day, with no clear changes and few detections for movement metrics to consider when inferring fate (Fig. 3k, l). This fish was likely predated because the tag triggered, but with a small amount of data both before and after the code switched, inferring predation is based solely on this tag and is reliant on manufacturer standards for low rates of false positives.

\section{Discussion}

In this study, we delineated detection histories of triggered predation tags into stages so that they could be compared amongst each other, examined the total 
Table 3 Comparison of step lengths estimating linear distances between yellow perch centres of activity (COAs) for each day before and after apparent predation

\begin{tabular}{|c|c|c|c|c|c|c|}
\hline \multirow[t]{2}{*}{ Fish ID } & \multicolumn{2}{|l|}{ Before predation } & \multicolumn{2}{|l|}{ After predation } & \multicolumn{2}{|l|}{ Comparison } \\
\hline & $\begin{array}{l}\text { Daily mean step } \\
\text { lengths }(m)\end{array}$ & Number of days & $\begin{array}{l}\text { Daily mean step } \\
\text { lengths }(m)\end{array}$ & Number of days & $\begin{array}{l}\text { Difference in daily } \\
\text { means }(\mathrm{m})\end{array}$ & Change \\
\hline YP02 & $848.8 \pm 72.2$ & 42 & 99.8 & 1 & -747.0 & $-88 \%$ \\
\hline YP10 & $860.0 \pm 171.0$ & 9 & $1445.0 \pm 970.3$ & 2 & +585.0 & $+68 \%$ \\
\hline YP12 & $764.0 \pm 100.9$ & 33 & $400.1 \pm 92.8$ & 18 & -364.0 & $-48 \%$ \\
\hline YP17 & $454.9 \pm 71.8$ & 18 & - & - & - & - \\
\hline YP19 & $482.2 \pm 60.9$ & 53 & $473.3 \pm 70.1$ & 11 & -9.0 & $-2 \%$ \\
\hline YP22 & $541.0 \pm 86.4$ & 14 & $334.8 \pm 273.1$ & 2 & -206.2 & $-38 \%$ \\
\hline YP23 & - & - & $755.69 \pm 413.1$ & 3 & - & - \\
\hline YP26 & $432.2 \pm 59.7$ & 24 & - & - & - & - \\
\hline YP33 & - & - & 78.1 & 1 & - & - \\
\hline YP34 & $519.6 \pm 234.0$ & 2 & $982.83 \pm 14.4$ & 2 & +463.2 & $+89 \%$ \\
\hline YP38 & $413.0 \pm 55.8$ & 45 & 317.6 & 1 & -95.4 & $-23 \%$ \\
\hline YP39 & $379.6 \pm 62.1$ & 30 & - & - & - & - \\
\hline YP42 & - & - & 199.6 & 1 & - & - \\
\hline YP43 & $230.7 \pm 85.5$ & 16 & 109.5 & 1 & -121.2 & $-53 \%$ \\
\hline YP44 & $216.1 \pm 59.3$ & 11 & $1870.9 \pm 1055.3$ & 3 & +1654.7 & $+766 \%$ \\
\hline YP47 & $555.5 \pm 87.1$ & 24 & - & - & - & - \\
\hline YP51 & 172.0 & 1 & 51.3 & 1 & -120.6 & $-70 \%$ \\
\hline YP54 & $207.2 \pm 17.4$ & 15 & 50.5 & 1 & -156.7 & $-76 \%$ \\
\hline
\end{tabular}

behavioural variation across triggered tags using a variety of space use metrics, and synthesized this information to make inferences regarding the fates of each apparently predated fish. There are multiple possible interpretations for the movement patterns observed from predation tags that distinguish them from presence/absence tags most frequently used in acoustic telemetry studies. Tags that exhibited both a code switch and clear changes in space use before and after predation, e.g. location of activity or size of activity range, would have had the highest confidence of a predation event occurring due to the coupling of behaviour changes with the tag trigger mechanism.

The observed detection scenarios demonstrated the variety of predation tag patterns that were observed within a single study array over a relatively short period of time. Although the analytical metrics, i.e. roaming index, movement pathways, and step length distances, were likely to identify some predation events (e.g. YP10), there were multiple scenarios under which they alone were unlikely to indicate predation based both on the number of detections (e.g. YP23, YP42) and the behaviours of predators in comparison to perch (e.g. YP38). As predation tags are a new technology, at this time we argue that rather than using the tags as the only indicator of predation, examining each individual using multiple metrics of habitat use combined with predation tags allowed for informed decision-making about the fates of tagged fish while acknowledging uncertainty surrounding predation events. As more studies find strong and consistent evidence that predation tags are performing well in the environment, assigning a fate of predated based solely on the switch in signal from the tags is likely.

Apparent predation events based on a code switch with few detections or those that did not have distinct changes in space use patterns followed by a drop in activity were unlikely to be detected without the use of predation tags. However, predation tags do not necessarily indicate all predation events that occur in wild systems because of limitations inherent in most acoustic telemetry studies. Specific to the acoustic array used here, predation levels could be underestimated if predators that consume tagged fish leave the receiver array during the signal lag period of the predation transmitter. Indeed, of the 41 tagged fish that were not indicated as predated in this study, 26 were no longer detected in the array before the end of their battery lifespan and were assumed to have moved out of the receiver's detection range. Other receiver configurations, e.g. a broader distribution along the length of the river, may have increased the probability of detecting predation events that involved perch being carried away, but would have come at the cost of the resources needed to establish a larger array-a trade-off most acoustic telemetry studies face. As such, predation levels here 
Table 4 Summary of assumed fate for each tagged yellow perch detected as predated

\begin{tabular}{|c|c|c|c|}
\hline Tag ID & $\begin{array}{l}\text { Day of first } \\
\text { predation } \\
\text { detection }\end{array}$ & Fate & Justification \\
\hline YPO2 & 99 & Predated & $\begin{array}{l}\text { Increase in spatial use following code switch then a detection pattern consistent with a } \\
\text { predator-expelled tag after a gap in detections }\end{array}$ \\
\hline YP10* & 10 & Predated & $\begin{array}{l}\text { Sudden increase in spatial use surrounding predation event and change in habitat use post- } \\
\text { predation }\end{array}$ \\
\hline YP12 & 55 & Unclear-transmitter only & Similar spatial use before and after code switch \\
\hline YP17 & 71 & Unclear-transmitter only & $\begin{array}{l}\text { Few post-predation detections, but } 2 \text { of } 3 \text { post-predation detections occurred on the same } \\
\text { receiver months apart consistent with tag expelled from a predator. Since activity levels were } \\
\text { low prior to predation, it is possible that this tag falsely triggered inside of a dead tagged fish. } \\
\text { Post-predation detections would be removed by most false detection filters }\end{array}$ \\
\hline YP19 & 88 & Predated & $\begin{array}{l}\text { Reduced spatial use and detection pattern post-predation consistent with dropped tag. First } \\
\text { post-predation detection occurs after a gap in detections, perhaps predated }>24 \text { h before } \\
\text { first post-predation detection }\end{array}$ \\
\hline$Y P 22^{*}$ & 18 & Predated & Clear change in habitat use \\
\hline YP23* & 1 & Predated & Predated soon after release. Tag is clearly dropped \\
\hline YP26 & 32 & Predated & $\begin{array}{l}\text { Decrease in spatial use change surrounding code switch. Few post-predation detections all on } \\
\text { one receiver consistent with tag expelled from predator }\end{array}$ \\
\hline YP33 & 24 & Unclear-transmitter only & $\begin{array}{l}\text { Code switched after a gap in detections. Too few detections over a short period of time (4 days } \\
\text { with detections across } 24 \text { days total) }\end{array}$ \\
\hline YP34 & 2 & Predated & Increase in spatial use following code switch \\
\hline YP38* & 95 & Predated & No clear changes. Detections cease soon after tag triggers. Predator likely left study area \\
\hline YP39* & 94 & Predated & No clear spatial use changes but eventually detected as dropped \\
\hline YP42* & 3 & Unclear-transmitter only & $\begin{array}{l}\text { Detected for } 4 \text { days total. Possibly a false positive, more likely a predation event soon after } \\
\text { surgery and release when predator avoidance may have been hindered }\end{array}$ \\
\hline YP43 & 37 & Predated & No clear change in spatial use but tag appears dropped across 5-month period \\
\hline YP44 & 26 & Predated & Clear changes in spatial use and clear dropped tag across 5 months \\
\hline YP47 & 29 & Predated & Sudden decrease in spatial use. Only 11 post-predation detections on 1 day \\
\hline YP51 & 3 & Predated & Code switch soon after release. Clear dropped tag after 3-month gap in detections \\
\hline YP52 & 2 & Predated & $\begin{array}{l}\text { Code switched soon after release. Only ever detected on two receivers. Clear dropped tag after } \\
\text { 3-month gap in detections }\end{array}$ \\
\hline YP54 & 32 & Predated & $\begin{array}{l}\text { No clear changes but movements sustained surrounding predation event, few post-predation } \\
\text { detections but tag appears to have been expelled by predator }\end{array}$ \\
\hline
\end{tabular}

Included are the Tag ID, the number of days post-release upon which the first post-predation signal occurred, the assigned fate based on tag and movement data, and the justification used for the classification. Focal individuals highlighted in Fig. 3 are marked with an asterisk

likely produced a minimum predation level estimate, but came at the advantage of finer-scale observations of tagged fish movements.

Although the predation events in this study occurred over consistent environmental conditions, changes in the environment can affect the performance of acoustic tags and receivers and should be considered under variable conditions. For example, triggered tags may not be detected for weeks or months after a predation event until changes in receiver detection range, known to happen seasonally in both marine and freshwater systems [17], make them detectable long after a predation event, adding uncertainty to the location and timing of predation events. Predation tags do not replace the need for researchers to consider both the detection histories of each individual and the variables likely to influence acoustic receiver performance, ultimately using their best judgement of the study system and species involved to present arguments for the likely fates of tagged animals.

The variation in behaviour post tag-switch suggests that there may have been different predators in the system, consistent with the diversity of predators known to inhabit this area of the Detroit River $[8,9]$. In the past, telemetry studies have inferred predation or mortality via behavioural changes that were deemed atypical of the study species, mirrored known behaviour of another species, or resulted in ceased movement $[2,18]$. These past techniques are likely to be reliable only in systems where there are relatively few predators that show consistent behaviours, limiting their application to diverse communities with variety of predators that differ in habitat and foraging behaviours. Pairing predation tags with methods used in the many telemetry studies that have been able to show support of predation has the potential to produce 


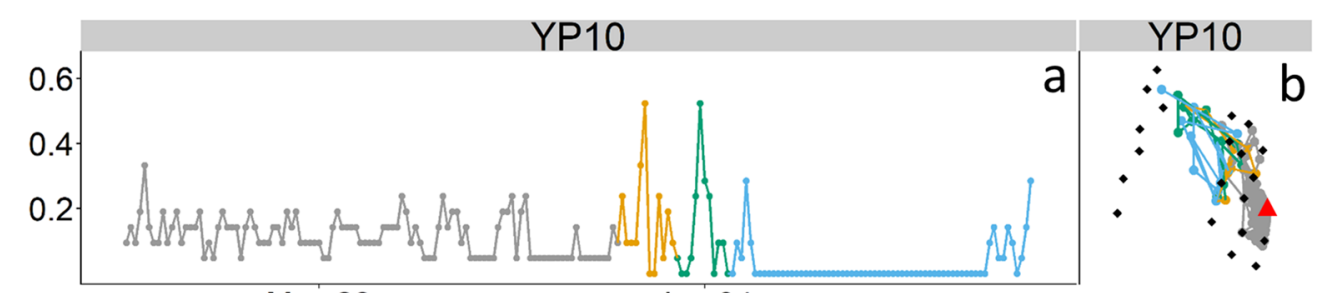

May 28 Jun 04
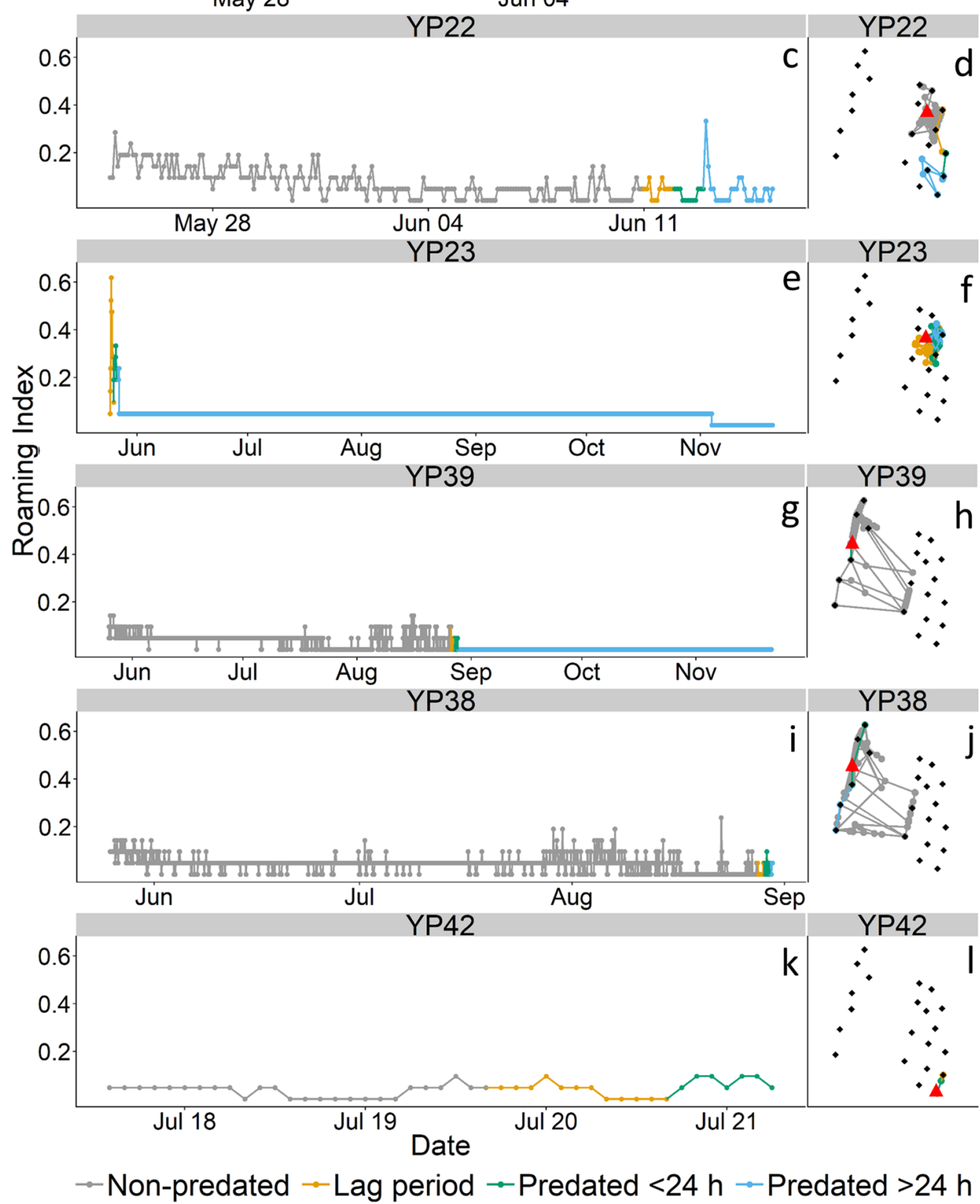

Fig. 3 Roaming index plots (left) and movement paths (right) of six apparently predated yellow perch in the Detroit River across May-November 2018. Roaming indices were calculated as the number of receivers that each tag was detected on per 2-h period as a proportion of the total number of receivers in the array; values of zero indicate periods with no detections. Centres of activity (COA) used to plot the movement paths were calculated using a 30-min timestep. Black dots in movement path plots represent the 21 stations deployed in the Detroit River (see Fig. 1). Red triangles indicate the release point of the tagged fish 


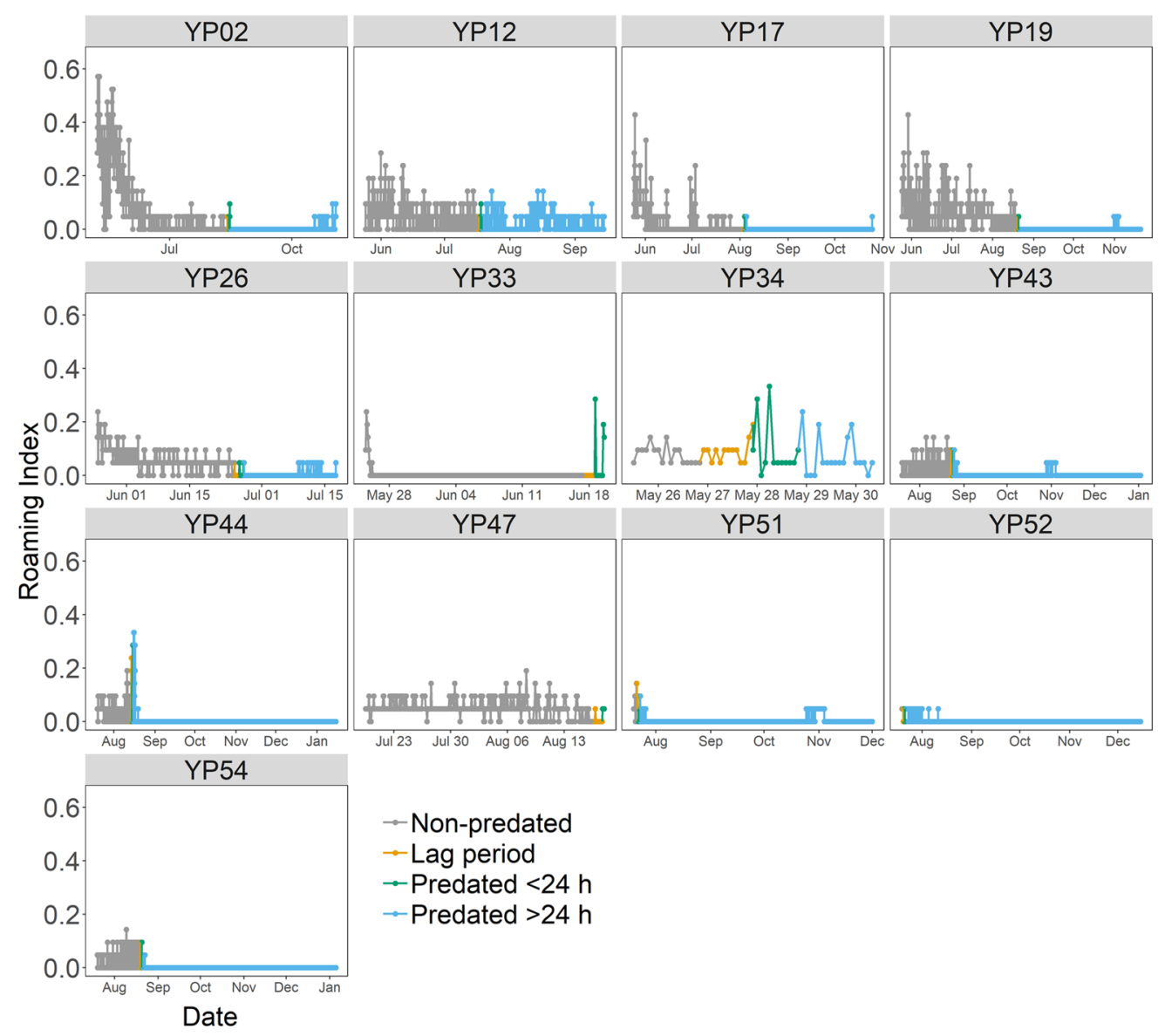

Fig. 4 Roaming index plots for remaining 13 triggered tags from May 2018-January 2019. Roaming indices were calculated as the number of receivers each tag was detected on per 2 -h period divided by the total number of receivers in the array. Gaps in detections are represented by a roaming index value of zero. The date range presented in each panel is specific to each individual and reflects the period from their first to final detections

strong arguments for predation. Additionally, concurrent tagging of potential predators along with predationtagged prey fish could help aid in making inferences regarding the fate of tagged prey.

Acoustic telemetry is a growing tool and is influencing fisheries management and conservation, with potential to address the difficulty of quantifying mortality or survival rates [19]. Predation tags can provide one of the most difficult components of this estimatepredation, and have been used to estimate survival of Atlantic salmon smolts migrating through the Miramichi River [6]. Importantly, they address the issue of "predation bias", which is incorporating telemetry data for tags that are in the GI tract of a predator in the analysis instead of the originally tagged fish species [6]. Incorporating data that does not originate from the tagged study animal can have large implications for how the data are analysed and the conclusions that are ultimately made. As most telemetry studies have focused on adult stages of larger more economically important species, the issue of predation has not been as relevant as it is for smaller-sized fish or juvenile stages, including those of economically important species. The use of predations tags is likely to be a key component for proper interpretation of telemetry results for fish vulnerable to predation, particularly for management and conservation.

As telemetry develops smaller tags, the interest in studying the movement, behaviour and fate of smaller fish has grown. Numerous species are hatchery-reared and released in large numbers with little known about predation levels following release $[6,20,21]$. The use of predation tags could contribute to estimates of poststocking mortality, e.g. predation of hatchery-raised fish in Lake Ontario [5], that can be used to inform stocking numbers and methods. Development of assessment tools, including predation tags that contribute to increased stocking success can benefit the management 


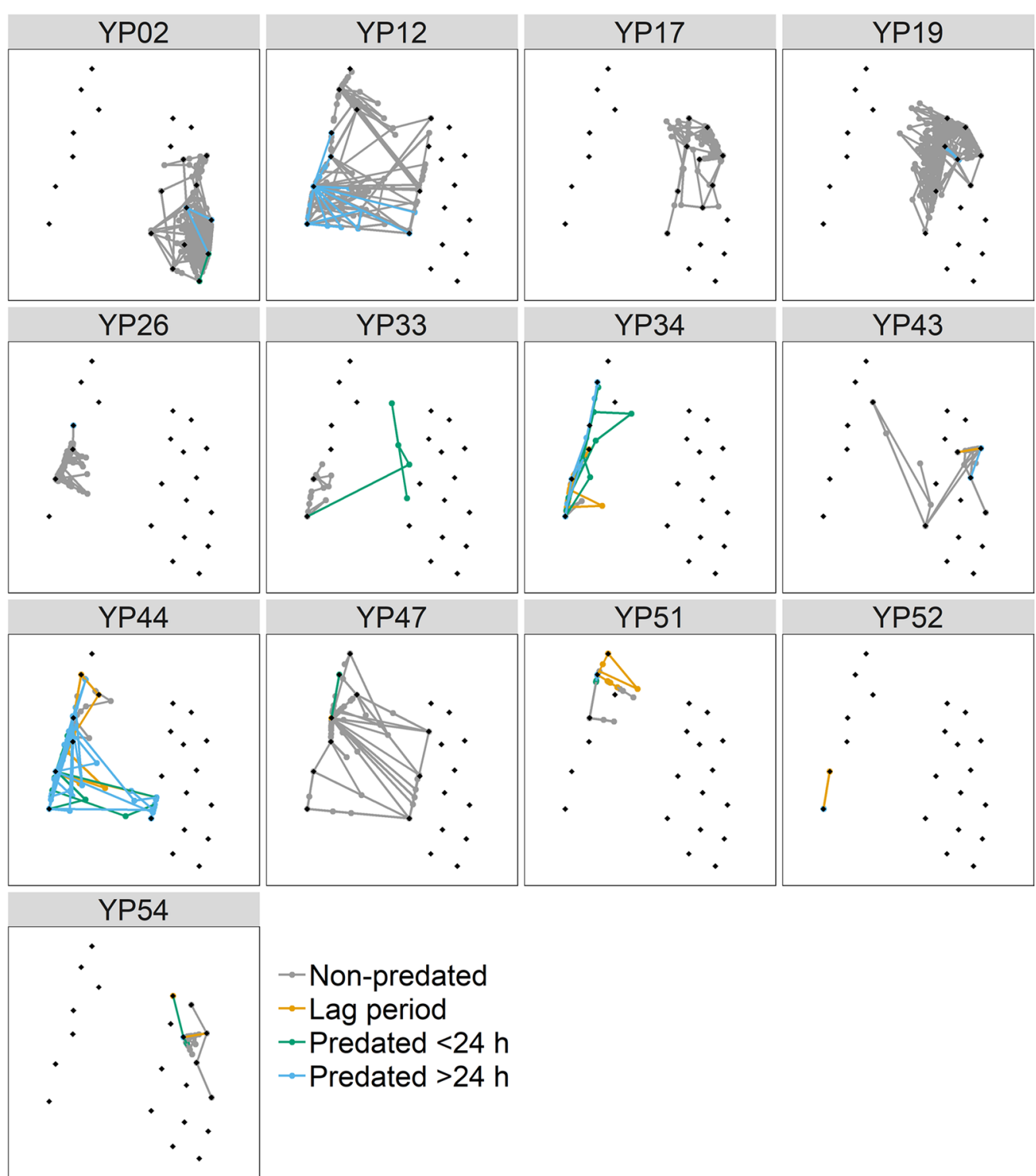

Fig. 5 Centres of activity (COA) for remaining 13 triggered tags. COAs were calculated as the average position of the tag within a 30-min timestep. Black dots represent station locations in the Detroit River (see Fig. 1)

of economically important species and the restoration of aquatic communities.

In addition to a variety of ecological questions that could be asked using predation tags, they can also serve as a tool for evaluating the effects of human interactions and stocking on tagged animals. For example, the process of capturing and surgically implanting tags in fish can influence post-release behaviour [22, 23] and predation tags present the opportunity to establish if predation levels are elevated for a period following tagging and release [22, 24]. In our study, Tag YP23 was apparently consumed within hours of tagging, which may have been caused by reduced predator evasion due to tagging effects, despite efforts made to reduce the stress of handling, surgery, and optimize recovery time. We observed a total of five predation events that occurred within 3 days of tagging, a window during which it is conceivable that fish have increased vulnerability to predation due to surgeries. Although our observation of five predation events within 3 days of tagging is unlikely to be interpreted as a significant tagging effect on survival, it was the use of predation tags that provided the support to reach this conclusion. 


\section{Conclusions}

Gaining insight into natural mortality of animals in aquatic ecosystems has proven to be difficult in the past and methods are often indirect or labour-intensive. Acoustic telemetry is a valuable tool used to learn about the behaviour and survival of aquatic animals, but until recently had limited ability to provide evidence of mortality, particularly predation-induced mortality. We have demonstrated one of the first applications of predation tags designed to specifically identify predation events in natural settings and provide evidence that the tags function effectively based on behavioural changes before and after predation. While these predation tags do not remove all uncertainty about the fate of tagged individuals, they provide a level of inferential power not previously available to telemetry studies and open new avenues for insights into spatial ecology of wild populations.

\section{Acknowledgements}

The authors would like to thank all of those who helped in the field with fish tagging and receiver array maintenance (M. Charron, F. Cullen, T. Fendler, L. Fisk, Z. Fisk, J. Galasso, K. Hudelson, C. Heuvel, K. Johnson, S. Larocque, T. Leadley, M. Lucas, M. McCabe, B. Nawrocki, I. Smith). Feedback from anonymous reviewers helped to improve this manuscript. This paper is contribution \#86 of the Great Lakes Acoustic Telemetry Observation System (GLATOS).

\section{Authors' contributions}

AAW, ATF and SFC conceived and designed the project. AAW led the field work, data analysis (with help from JKM and SFC), and writing of the manuscript, with all other authors contributing to the research and writing of the manuscript. All authors read and approved the final manuscript.

\section{Funding}

Research was funded by an NSERC Discovery and Canada Research Chair funds to A.T.F. J.K.M. was supported by CIGLR post-doctoral funds.

\section{Availability of data and materials}

The datasets used and/or analysed during the current study are available from the corresponding author on reasonable request.

\section{Ethics approval and consent to participate}

Research activities were carried out under MNRF permit LE-04-2018 issued to Aaron Fisk. Research was approved by the University of Windsor Animal Care Committee (AUPP 18-06).

\section{Consent for publication}

Not applicable.

\section{Competing interests}

The authors declare that they have no competing interests.

\section{Author details}

${ }^{1}$ Great Lakes Institute for Environmental Research, University of Windsor, Windsor, ON, Canada. ${ }^{2}$ Present Address: Department of Biology, Dalhousie University, Halifax, NS, Canada. ${ }^{3}$ Daniel P. Haerther Center for Conservation and Research, Shedd Aquarium, Chicago, IL, USA.

Received: 14 October 2019 Accepted: 25 July 2020

Published online: 09 August 2020

\section{References}

1. Hussey NE, Kessel ST, Aarestrup K, Cooke SJ, Cowley PD, Fisk AT, et al. Aquatic animal telemetry: a panoramic window into the underwater world. Science. 2015;348(6240):1255642

2. Gibson AJF, Halfyard EA, Bradford RG, Stokesbury MJW, Redden AM. Effects of predation on telemetry-based survival estimates: insights from a study on endangered Atlantic salmon smolts. Can J Fish Aquat Sci. 2015;72(5):728-41.

3. Béguer-Pon M, Campana SE, Aarestrup K, Castonguay M, Benchetrit J, Stokesbury MJW, et al. Shark predation on migrating adult American eels (Anguilla rostrata) in the Gulf of St. Lawrence. PLoS ONE. 2012;7(10):e46830.

4. Halfyard EA, Webber D, Del Papa J, Leadley T, Kessel ST, Colborne SF, et al. Evaluation of an acoustic telemetry transmitter designed to identify predation events. Methods Ecol Evol. 2017;8(9):1063-71.

5. Klinard NV, Matley JK, Halfyard EA, Connerton M, Johnson TB, Fisk AT. Poststocking movement and survival of hatchery-reared bloater (Coregonus hoyi) reintroduced to Lake Ontario. Freshw Biol. 2020;65(6):1073-85.

6. Daniels J, Sutton S, Webber D, Carr J. Extent of predation bias present in migration survival and timing of Atlantic salmon smolt (Salmo salar) as suggested by a novel acoustic tag. Anim Biotelemetry. 2019;7(16):1-11.

7. Klinard NV, Halfyard EA, Fisk AT, Stewart TJ, Johnson TB. Effects of surgically implanted acoustic tags on body condition, growth, and survival in a small, laterally compressed forage fish. Trans Am Fish Soc. 2018;147(4):749-57.

8. Lapointe NWR. Effects of shoreline type, riparian zone and instream microhabitat on fish species richness and abundance in the Detroit River. J Great Lakes Res. 2014;40(Suppl 2):62-8.

9. Lapointe NWR, Corkum LD, Mandrak NE. Macrohabitat associations of fishes in shallow waters of the Detroit River. J Fish Biol. 2010;76(3):446-66.

10. Brown RS, Harnish RA, Carter KM, Boyd JW, Deters KA, Eppard MB. An evaluation of the maximum tag burden for implantation of acoustic transmitters in juvenile chinook salmon. North Am J Fish Manag. 2010;30(2):499-505.

11. Smircich MG, Kelly JT. Extending the $2 \%$ rule: the effects of heavy internal tags on stress physiology, swimming performance, and growth in brook trout. Anim Biotelemetry. 2014;2:16

12. Kim J, Doyle B, Mandrak NE. Electrosedation of freshwater fishes for the surgical implantation of transmitters. Can J Zool. 2017;95(8):575-80.

13. Trushenski JT, Bowker JD, Mulligan BL, Gause BR. Induction, recovery, and hematological responses of largemouth bass to chemo- and electrosedation. N Am J Aquac. 2012;74(2):214-23.

14. Matley JK, Heupel MR, Simpfendorfer CA. Depth and space use of leopard coral grouper Plectropomus leopardus using passive acoustic tracking. Mar Ecol Prog Ser. 2015;521:201-16.

15. Simpfendorfer CA, Heupel MR, Hueter RE. Estimation of short-term centers of activity from an array of omnidirectional hydrophones and its use in studying animal movements. Can J Fish Aquat Sci. 2002;59:23-32.

16. Simpfendorfer CA, Huveneers C, Steckenreuter A, Tattersall K, Hoenner $X$, Harcourt R, et al. Ghosts in the data: false detections in VEMCO pulse position modulation acoustic telemetry monitoring equipment. Anim Biotelemetry. 2015;3:55.

17. Kessel ST, Cooke SJ, Heupel MR, Hussey NE, Simpfendorfer CA, Vagle $\mathrm{S}$, et al. A review of detection range testing in aquatic passive acoustic telemetry studies. Rev Fish Biol Fish. 2014;24:199-218.

18. FriedI SE, Buckel JA, Hightower JE, Scharf FS, Pollock KH. Telemetry-based mortality estimates of juvenile spot in two North Carolina estuarine creeks. Trans Am Fish Soc. 2013;142(2):399-415.

19. Krueger CC, Holbrook CM, Binder TR, Vandergoot CS, Hayden TA, Hondorp DW, et al. Acoustic telemetry observation systems: challenges encountered and overcome in the Laurentian Great Lakes. Can J Fish Aquat Sci. 2018;75(10):1755-63.

20. Flowers HJ, Kwak TJ, Fischer JR, Cope WG, Rash JM, Besler DA. Behavior and survival of stocked trout in southern Appalachian Mountain streams. Trans Am Fish Soc. 2019;148:3-20.

21. Bettinger JM, Bettoli PW. Fate, dispersal, and persistence of recently stocked and resident rainbow trout in a Tennessee tailwater. North Am J Fish Manag. 2002;22(2):425-32.

22. Wilson ADM, Hayden TA, Vandergoot CS, Kraus RT, Dettmers JM, Cooke SJ, et al. Do intracoelomic telemetry transmitters alter the post-release behaviour of migratory fish? Ecol Freshw Fish. 2017;26(2):292-300. 
23. Cooke SJ, Woodley CM, Eppard MB, Brown RS, Nielsen JL. Advancing the surgical implantation of electronic tags in fish: a gap analysis and research agenda based on a review of trends in intracoelomic tagging effects studies. Rev Fish Biol Fish. 2011;21:127-51.

24. Adams NS, Rondorf DW, Evans SD, Kelly JE, Perry RW. Effects of surgically and gastrically implanted radio transmitters on swimming performance and predator avoidance of juvenile chinook salmon (Oncorhynchus tshawytscha). Can J Fish Aquat Sci. 1998;55(4):781-7.

\section{Publisher's Note}

Springer Nature remains neutral with regard to jurisdictional claims in published maps and institutional affiliations.
Ready to submit your research? Choose BMC and benefit from:

- fast, convenient online submission

- thorough peer review by experienced researchers in your field

- rapid publication on acceptance

- support for research data, including large and complex data types

- gold Open Access which fosters wider collaboration and increased citations

- maximum visibility for your research: over $100 \mathrm{M}$ website views per year

At BMC, research is always in progress.

Learn more biomedcentral.com/submissions 